\title{
A STATISTICAL ANALYSIS OF OBSTETRIC AND PERINATAL COMPLICATIONS IN SINGLETON AND MULTIPLE PREGNANCIES ONCE ASSISTED REPRODUCTIVE TECHNOLOGIES ARE USED
}

DOI: 10.36740/WLek202104120

\author{
Tamara H. Romanenko ${ }^{1}$, Olha M. Sulimenko ${ }^{1,2}$, Svitlana 0. Ovcharenko ${ }^{2}$ \\ 'SHUPYK NATIONAL MEDICAL ACADEMY OF POSTGRADUATE EDUCATION THE MINISTRY OF HEALTH OF UKRAINE, KYIV, UKRAINE \\ ${ }^{2}$ LELEKA MATERNITY HOSPITAL LLC, KYIV, UKRAINE
}

\begin{abstract}
The aim: To carry out a comparative statistical analysis of obstetric and perinatal complications in singleton and multiple pregnancies once assisted reproductive technologies (ART) are applied according to the records taken from archival materials (maternity and delivery records) and identify the clinical features of multiple pregnancy.

Materials and methods: Over the period of 2017-2019, 522 women gave birth in LELEKA Maternity Hospital LLC after using assisted reproductive technologies and 331 women among them were followed-up in the women's health center of LELEKA maternity hospital. Among these women (522) with singleton pregnancy 445 women gave birth, while in multiple pregnancy -77 .

The statistical analysis of 150 maternity and delivery records was carried out. All pregnant women were divided into two groups: group 1- 75 women having singleton pregnancy after ART; group 2 - 75 women having multiple pregnancy after ART. Women getting pregnant after ART, or in vitro fertilization (IVF) and five-day frozen embryo transfer to be exact, turned out to be the selection criterion for a comparative statistical analysis. Mathematical methods for research were used as 0.P. Mintser (2013) suggested. The reliability of the digit cancellation test was calculated using the Fisher's exact test and Student's T-test. Graphs were designed using Microsoft Excel.

Results: The complications of early multiple pregnancy were the following: anemia (47.8\% as opposed to $22.9 \%, \mathrm{p}<0.01$ ), placental insufficiency ( $43.3 \%$ in contrast to $22.9 \%$, $\mathrm{p}<0.01$ ), threatened abortion ( $41.8 \%$ in contrast to $28.6 \%, \mathrm{p}<0.01)$. The complications in late pregnancy are as follows: preeclampsia ( $52.7 \%$ as opposed to $20.6 \%, \mathrm{p}<0.01)$, intrauterine growth restriction ( $20.0 \%$ as opposed to $7.4 \%, p<0.01)$, anemia in pregnancy $(76.4 \%$ in contrast to $32.4 \%, p<0.01)$, placental insufficiency ( $47.3 \%$ in contrast to $22.1 \%, \mathrm{p}<0.05)$.

Conclusions: Multiple pregnancy is a high risk for anemia in pregnancy, preeclampsia, placental insufficiency, early intrauterine growth restriction and fetal distress in pregnancy and labor. It predetermines the high level of a caesarean section. Therefore, further research aimed at prediction and prevention of obstetric and perinatal complications in multiple pregnancy after ART is currently topical.
\end{abstract}

KEY WORDS: obstetric and perinatal complications, multiple pregnancy, assisted reproductive technologies

Wiad Lek. 2021;74(4):915-922

\section{INTRODUCTION}

The use of assisted reproductive technologies (ART) enables to effectively fight infertility off over the past 40 years. More than 5 million infants worldwide were born once ART had been applied in infertility $[1,2]$. However, getting pregnancy using ART is only the first stage, while the birth of a healthy newborn depends on the course and management of pregnancy and childbirth for sure. Characteristics of multiple pregnancy, once ART is applied, hold an exceptional interest for applied science, at the stages of embryo implantation and placentation in particular. Thus, despite the widespread adoption of ART for assisted conception, the matter of enhancing the ART effectiveness still remains relevant, as well as optimizing the management of labor and delivery since the early gestational age in order to minimize risks for both a mother and her child. Just over the last couple of years the incidence of multiple pregnancy rapidly grew, and ranges from $0.7 \%$ to $1.5 \%$ in the majority of European countries. According to the registries by the
European Society of Human Reproduction and Embryology (ESHRE) the effectiveness of ART programs today is nearly $40 \%$. More than 1.8 million children were born in Ukraine in 2019, 27 thousand (1.6\%) of which - after ART program $[1,2]$. The occurrence of twin pregnancy in the natural cycle is low and according to different researchers, ranges from 11 to 14 per 1000 deliveries, the use of ART led to a 20-time increase in the number of multiple pregnancies comparing to a natural population [2]. Over the last 10 years, the number of deliveries of twins increased by $27 \%$, triplets - by $38 \%$. These days iatrogenic multiple pregnancy comprises $30-80 \%$ among multiple pregnancies. Delivery of twins account for $20-30 \%$, triplets $-4-6 \%$ among pregnancies that develop after ART. It is no secret that multiple pregnancy is associated with a high rate of adverse perinatal outcomes [2-5]. Statistics show that only $11-15 \%$ of multiple pregnancies and labors occur without complications. Perinatal mortality in delivery of more than one is 3 to 7 times higher than in singleton pregnancy [2- 
6]. It is known that multiple pregnancy itself determines a high risk of perinatal pathology. The high prevalence of threatened abortion with retroplacental hematoma as comorbidity is observed (the incidence of retrochorial hematoma during the first trimester in pregnancies after ART comprised 13.5\%) [7]. The prevalence of miscarriage in pregnancy after ART is $18-44.4 \%$, while the prevalence of preterm labor ranges from $19.5 \%$ to $37.6 \%$, the prevalence of gestational hypertension after ART was registered in $5.9 \%$ in singleton pregnancy and in $12.6 \%$ in multiple pregnancy. According to ACOG [2,6-11] the higher risk of preeclampsia (OR 2.7) turned out to be associated with ART [2, 6-11]. Preeclampsia (PE) still remains a global health issue, threatens maternal health and life $[2,11]$. PE holds $9-26 \%$ of maternal mortality and high percentage of preterm labor, predetermines both maternal and neonatal morbidity $[2,12]$. Statistics suggest that the prevalence of severe PE in multiple pregnancy is 3-4 times higher than in singleton pregnancy $[2,11,13-16]$.

\section{THE AIM}

To carry out a comparative statistical analysis of obstetric and perinatal complications in singleton and multiple pregnancies once assisted reproductive technologies (ART) are used according to the records taken from archival materials (maternity and delivery records) and identify the clinical features of multiple pregnancy.

\section{MATERIALS AND METHODS}

Over the period of 2017-2019, 522 women gave birth in LELEKA Maternity Hospital LLC after using assisted reproductive technologies and 331 women among them were followed-up in the women's health center of LELEKA maternity hospital. Among these women (522) with singleton pregnancy 445 women gave birth, while in multiple pregnancy - 77 .

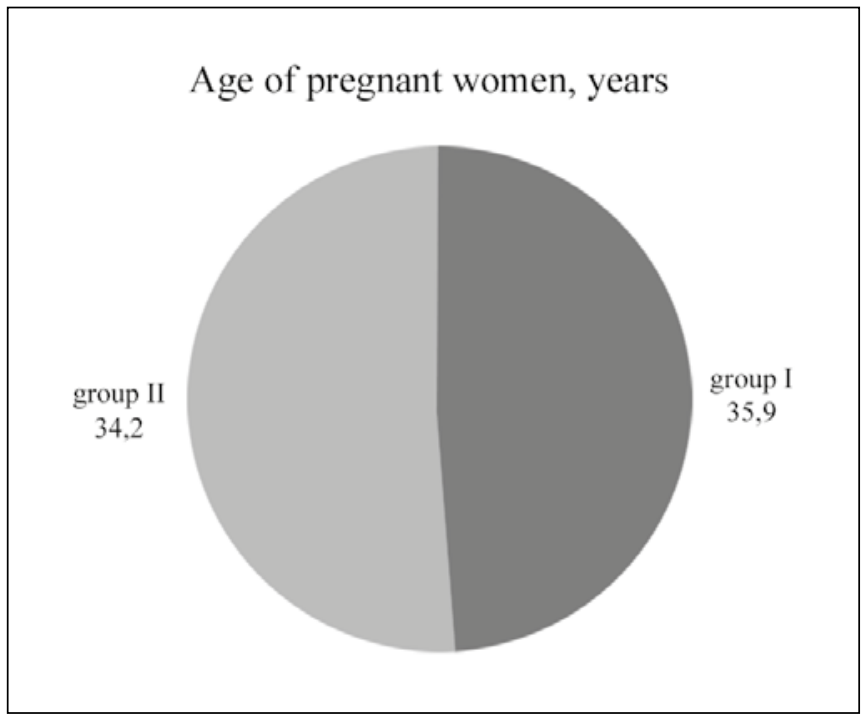

Fig. 1. Mean age of women examined (year $M \pm m$ )

The statistical analysis of 150 maternity and delivery records was carried out. All pregnant women were divided into two groups: group $1-75$ women having singleton pregnancy after ART; group 2 - 75 women having multiple pregnancy after ART. Women getting pregnant after ART, or in vitro fertilization (IVF) and five-day frozen embryo transfer to be exact, turned out to be the selection criterion for a comparative statistical analysis. Mathematical methods for research were used as O.P. Mintser (2013) suggested. The reliability of the digit cancellation test was calculated using the Fisher's exact test and Student's T-test. Graphs were designed using Microsoft Excel.

\section{RESULTS AND DISCUSSION}

The majority of women examined were women aged 25-45 with infertility lasting 3-9 years. The mean age of women did

Table I. Extragenital diseases in women examined (abs. n., \%)

\begin{tabular}{ccc}
\hline Extragenital diseases & \multicolumn{2}{c}{ Groups of women } \\
\cline { 2 - 3 } & $\begin{array}{c}\text { Group 1 } \\
\mathbf{n = 7 5}\end{array}$ & $\begin{array}{c}\text { Group 2 } \\
\mathbf{n}=\mathbf{7 5}\end{array}$ \\
\hline Diabetes mellitus & $2(2.7 \%)$ & $5(6.7 \%)^{*}$ \\
\hline Rheumatoid arthritis, congenital heart defects & $2(2.7 \%)$ & $2(2.7 \%)$ \\
\hline Hypertension & $2(2.7 \%)$ & $5(6.7 \%)^{*}$ \\
\hline Chronic obstructive pulmonary diseases & $2(2.7 \%)$ & $3(4 \%)$ \\
\hline Chronic urinary tract infections & $6(8 \%)$ & $7(9.3 \%)$ \\
\hline Hepatitis and cholecystitis & $6(8 \%)$ & $7(9,3 \%)$ \\
\hline Varicose veins & $5(6.7 \%)$ & $4(5.3 \%)$ \\
\hline Anemia & $6(8 \%)$ & $10(13.7 \%)^{*}$ \\
\hline Myopia & $1(1.3 \%)$ & $2(2.7 \%)$ \\
\hline Thyroid disease & $7(9.3 \%)$ & $11(14.7 \%)^{*}$ \\
\hline Overall & $39(52 \%)$ & $56(74.7 \%)$ \\
\hline
\end{tabular}

Statistical significance of differences comparing to group $1 ;{ }^{*} p<0.05$ 

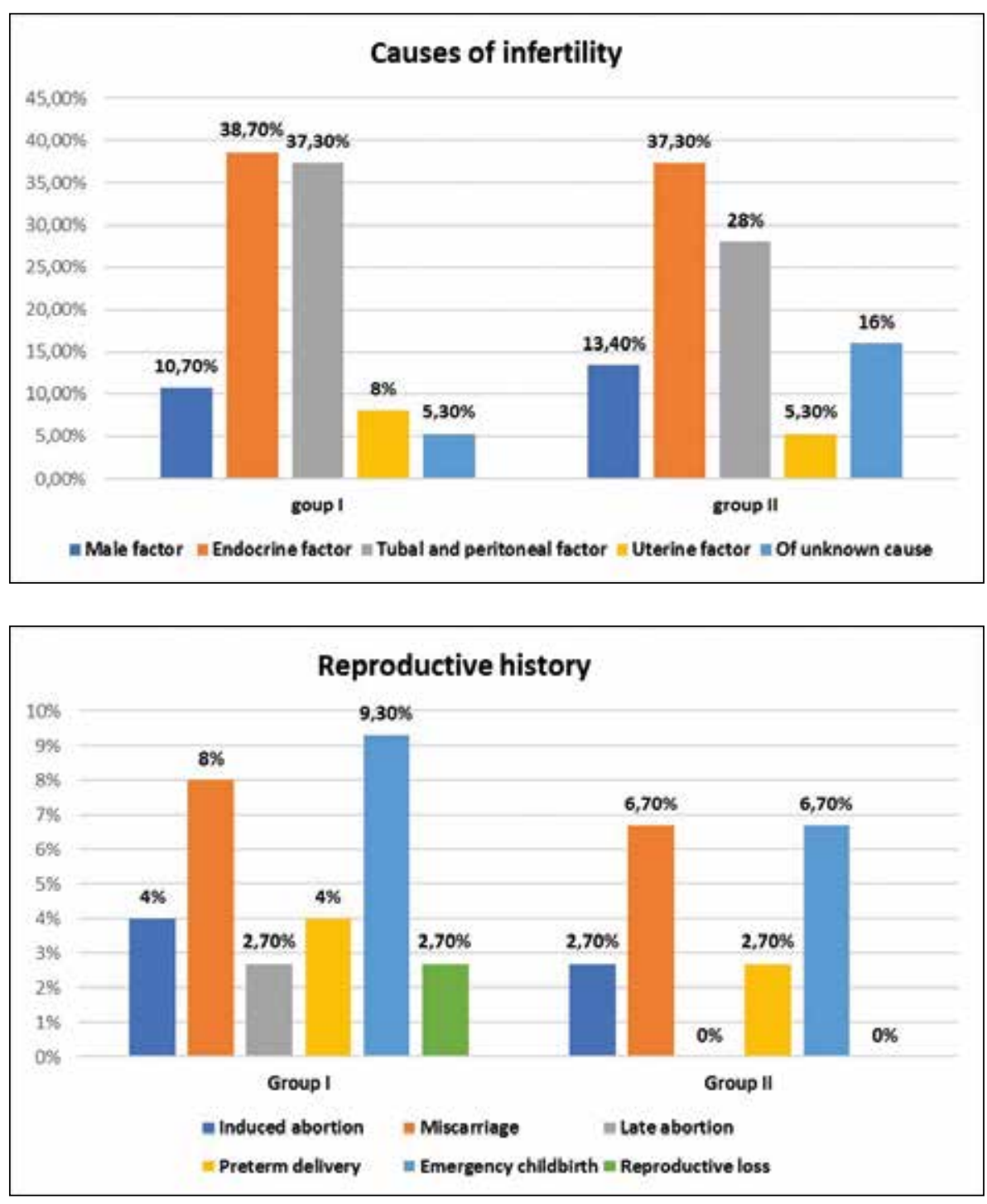

Fig. 3. Reproductive history (\%)

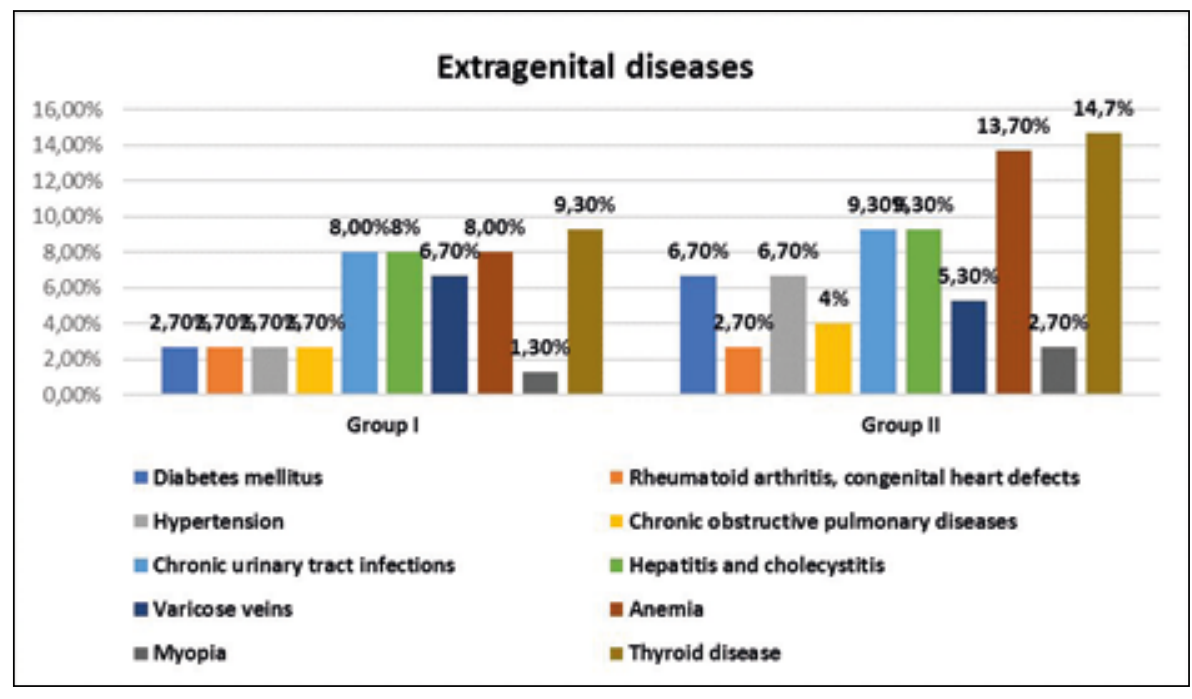

Fig. 2. Infertility causes in women examined (\%) not differ significantly by groups and turned out to be statistically insignificant ( $\mathrm{p}>0.05)$ as study results attest (Fig. 1).

Thus, the age of women having singleton pregnancy (group 1) averaged out at $34.2 \pm 2.1$ years. The mean age of women in group 2 was $35.9 \pm 2.2$ years. All women having induced pregnancy in groups 1 and 2 were registered in the women's health center.

Primary infertility was observed in $67.3 \%$ of all women examined, secondary infertility - in $32.7 \%$, the mean age of infertility was 3-6 years. It is worth mentioning that primary 

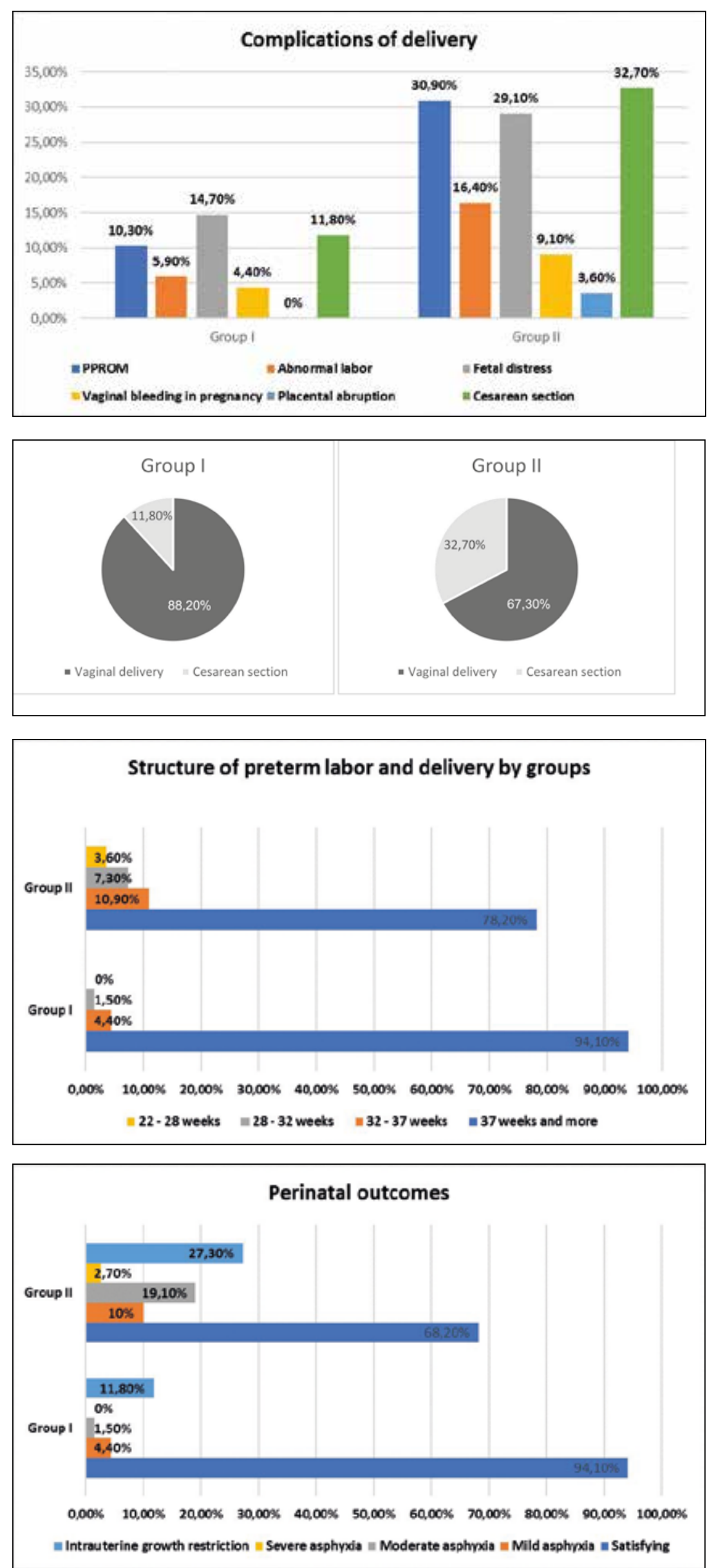

Fig. 5. Complications of delivery (\%)

Fig. 6. Principles of delivery in women examined (\%)

Fig. 7. Structure of preterm labor by groups (\%)

Fig. 8. Perinatal outcomes of birth (\%) 
Table II. Clinical features of early pregnancy (abs. n., \%)

\begin{tabular}{ccc} 
Complications & \multicolumn{2}{c}{ Groups of women } \\
\cline { 2 - 3 } & $\begin{array}{c}\text { Group I } \\
\mathbf{n = 7 0}\end{array}$ & $\begin{array}{c}\text { Group II } \\
\mathbf{n = 6 7}\end{array}$ \\
\hline Vomiting in pregnancy & $8(11.4 \%)$ & $11(16.4 \%)$ \\
\hline Threatened abortion & $20(28.6 \%)$ & $28(41.8 \%)^{* *}$ \\
\hline Anemia in pregnancy & $16(22.9 \%)$ & $32(47.8 \%)^{* *}$ \\
\hline Placental insufficiency & $16(22.9 \%)$ & $29(43.3 \%)^{* *}$ \\
\hline Exacerbation of a physical disorder & $8(11.4 \%)$ & $11(16.4 \%)$ \\
\hline
\end{tabular}

Statistical significance of differences comparing to group $1 ;{ }^{*} p<0.05 ;{ }^{* *} p<0.01$

Table III. Clinical features of late pregnancy (abs. n., \%)

\begin{tabular}{ccc}
\hline & \multicolumn{2}{c}{ Groups of women } \\
\cline { 2 - 3 } Complications & $\begin{array}{c}\text { Group I } \\
\mathbf{n = 6 8}\end{array}$ & $\begin{array}{c}\text { Group II } \\
\mathbf{n}=\mathbf{5 5}\end{array}$ \\
\hline Threatened abortion & $16(23.5 \%)$ & $31(56.4 \%)^{*}$ \\
\hline Anemia in pregnancy & $22(32.4 \%)$ & $42(76.4 \%)^{* *}$ \\
\hline Preeclampsia & $14(20.6 \%)$ & $29(52.7 \%)^{* *}$ \\
\hline Gestational hypertension & $6(8.8 \%)$ & $10(18.2 \%)^{*}$ \\
\hline Gestational diabetes & $10(14.7 \%)$ & $13(23.7 \%)^{*}$ \\
\hline Placental insufficiency & $15(22.1 \%)$ & $26(47.3 \%)^{*}$ \\
\hline Polyhydramnios & $4(5.9 \%)$ & $15(27.3 \%)$ \\
\hline Cervical weakness & $2(2.9 \%)$ & $7(12.7 \%)^{*}$ \\
\hline Exacerbation of a physical disorder & $9(13.2 \%)$ & $9(16.4 \%)$ \\
\hline IUGR & $5(7.4 \%)$ & $22(20 \%)^{* *}$ \\
$n=110$
\end{tabular}

Statistical significance of differences comparing to group $1 ;{ }^{*} p<0.05 ;{ }^{* *} p<0.01$

Table IV. Structure of indications for Cesarean section (abs. n. \%)

\begin{tabular}{|c|c|c|}
\hline Indications & $\begin{array}{c}\text { Group I } \\
\mathbf{n}=\mathbf{8}\end{array}$ & $\begin{array}{c}\text { Group II } \\
\mathbf{n}=18\end{array}$ \\
\hline IUGR & $1(12.5 \%)$ & $2(11.1 \%)$ \\
\hline Fetal distress & $3(37.5 \%)$ & $2(11.1 \%)$ \\
\hline Preeclampsia & - & $5(27.8 \%)$ \\
\hline Abnormal labor & $3(37.5 \%)$ & - \\
\hline Placental abruption & - & $3(16.7 \%)$ \\
\hline Others & $1(12.5 \%)$ & $6(33.3 \%)$ \\
\hline
\end{tabular}

Statistical significance of differences comparing to group $1 ;{ }^{*} \mathrm{p}<0.05$

infertility prevailed in women from group 2, in contrast to group 1 where secondary infertility prevailed. Infertility causes didn't vary by groups $(\mathrm{p}<0.05)$ and were categorized as follows (Fig. 2).

The findings of fertility health check are illustrated in figure 3, they indicate the absence of significant difference in reproductive history. At the same time, both groups are reported to have a low level of induced abortions ( $4 \%$ as opposed to $2.7 \%)$ and early threatened abortions ( $8 \%$ in contrast to $6.7 \%)(\mathrm{p}>0.05)$.

The level of reproductive loss in the past history (group 2 - absent, group $1-2.7 \%)$ and preterm labor (2.7\% in group
2 and $4.0 \%$ in group 1) are indicative. It can be explained by a significantly higher incidence of primary infertility in group 2 comparing to group $1(\mathrm{p}<0.05)$.

Regarding extragenital disease patterns in women examined we traced a significantly higher prevalence of diabetes mellitus, hypertension, anemia, thyroid diseases $(\mathrm{p}<0.05)$ in pregnant women of group 2 as opposed to group 1 (Table I).

According to our findings, the prevalence of extragenital diseases in women of group 1 comprised $74.7 \%-56$ women in contrast to $52 \%-39$ women of group 2 . This 
group included women with cardiovascular, pulmonary, endocrine, urologic and gastrointestinal diseases. Based on the prevalence and pattern of extragenital diseases the following diseases were of a significantly higher occurrence in group 2: diabetes mellitus, hypertension, anemia and thyroid diseases that, in our opinion, increase the risk of preeclampsia in women having multiple pregnancy.

The occurrence of extragenital diseases as comorbidity in groups studied was illustrated in figure 4 .

Thus, es evidenced by the study of premorbidity in groups of women having singleton and multiple pregnancies after ART we recognized the factors in women in case of multiple pregnancy that predispose to obstetric and perinatal complications in pregnancy. Data on gestation clinical features are very indicative when comparing (Table II). The main complications of early pregnancy in case of multiple pregnancy were: anemia ( $47.8 \%$ as opposed to $22.9 \%$, p $<0.01$ ), placental insufficiency ( $43.3 \%$ in contrast to $22.9 \%$, $\mathrm{p}<0.01)$, threatened abortion $(41.8 \%$ in contrast to $28.6 \%$, $\mathrm{p}<0,01)$. It is worth mentioning that in $36 \%$ of pregnant women in group 1 and $42.7 \%$ in group $2(\mathrm{p}<0.05)$ retroplacental hematomas are reported. Pregnancy ended up as miscarriage in 3 (4\%) pregnant women of group 1 during the first trimester and missed miscarriage in $2(2.7 \%)$ cases; 4 (5.3\%) cases of miscarriage and 4 (5.3\%) - missed miscarriage of the first trimester $(\mathrm{p}<0.05)$.

The same pattern took place after 20 weeks of pregnancy (Table III). Thus, 2 (2.9\%) cases of late abortion took place in group 1 as opposed to $7(10.5 \%)$ cases in group 2, $(\mathrm{p}<0.05)$. Three $(5 \%)$ cases of intrauterine death of both fetuses in patients of group 2 at 22-24 weeks should also be noted, as well as intrauterine death of only one fetus in 2 (3.3\%) cases, one case at 23 weeks and the other one at 28.

Various complications of pregnancy were observed almost in all women having multiple pregnancy. Thus, anemia in pregnancy was the most common - 42 (76.4\%) cases, threatened abortion - 31 (56.4\%) cases, preeclampsia $-29(52.7 \%)$ cases, placental insufficiency - $26(47.3 \%)$ cases, which led in the majority of cases to intrauterine growth restriction in 22 infants $(20 \%)^{* *}$.

In comparison, the occurrence of these complications in group 1, in singleton pregnancy, was substantially lower: anemia in pregnancy- $22(32.4 \%)$ cases, threatened abortion - $16(23.5 \%)$ cases, preeclampsia of various severity $-14(20.6 \%)$ cases and placental insufficiency - $15(22.1 \%)$, intrauterine growth restriction $-5(7.4 \%)$. The number of preeclampsia cases in women having multiple pregnancy was 2.6 times higher than in singleton pregnancy and comprised $52.7 \%(29)$ in contrast to $20.6 \%$ (14) in group $1(\mathrm{p}<0.01)$.

In multiple pregnancy placental insufficiency manifested as IUGR in $5(19.2 \%)$ patients, dissociated fetal development in $4(15.4 \%)$, while in $6(23.1 \%)$ cases dissociated fetal development was combined with growth restriction. Chronic placental insufficiency was compensated and confirmed by the findings of morphological analysis in $11(42.3 \%)$ cases.

As illustrated by figure 5, five main complications of delivery in women having multiple pregnancy were: premature rupture of membranes $(30.9 \%$ as opposed to $10.3 \%, \mathrm{p}<0.05)$, abnormal labor $(16.4 \%$ as opposed to $5.9 \%, \mathrm{p}>0.05)$, fetal distress $(29.1 \%$ in contrast to $14.7 \%$, $\mathrm{p}<0.05)$, placental abruption ( $3.6 \%$ as opposed to it's absence in group 1). This led in turn to an increase in the rate of Cesarean sections in women in case of multiple pregnancy.

Based on the data obtained when assessing delivery techniques, a significant increase in the rate $(32.7 \%)$ of Cesarean section in case of multiple pregnancy in contrast to $11.8 \%$ of patients in singleton pregnancy $(\mathrm{p}<0.01)$ should be noted (Fig.6).

Interestingly, the structure of indications for Cesarean section in women having multiple pregnancy (Table IV) was as follows: preeclampsia progression (27.8\%), IUGR (11.1\%), fetal distress (11.1\%), (16.7\%) - placental abruption, other indications ( breech and trunk presentation, oblique lie, clinical narrow pelvis, uterine scar) $-33.3 \%$. the Principal indications for Cesarean section in women of group 1 were the following: fetal distress with placental insufficiency as comorbidity (37.5\%), ineffective treatment of abnormal labor (37.3\%), other indications (breech and trunk presentation, oblique lie, clinical narrow pelvis, uterine scar) $-12.5 \%$.

The analysis of birth outcomes in all groups revealed that in patients of group 2 multiple pregnancy 3.7 times as often ended up prematurely as singleton $(21.8 \%$ and $5.9 \%, \mathrm{p}<0.05$ ). Almost half of the cases were deliveries at 34 weeks according to a gestation period, in other words, early preterm labor prevailed, $3.6 \%$ of which were deliveries at $22-28$ weeks, $7.3 \%$ - at $28-32$ weeks and $6.4 \%$ - at $32-34$ weeks (Fig. 7).

The average gestation period in singleton pregnancy herein comprised $37.6 \pm 1.2$ weeks, $35.1 \pm 1.3$ weeks - in multiple. Data on perinatal outcomes of birth are of substantial interest. When assessing perinatal outcomes of birth (Figure 8) a relevant increase in the sum rate of birth asphyxia of various severity in case of multiple pregnancy $(35.0 \%$ in contrast to $5.9 \%, \mathrm{p}<0.05)$, intrauterine growth restriction $(27.3 \%$ vs. $11.8 \%, p<0.01$ ) should be noted. Further, it affected the rate of early neonatal morbidity with delayed post-hypoxic leukoencephalopathy (23.6\%) being predominant in group 2 ; intrauterine infection (12.7\%); hemorrhagic syndrome (9.1\%) and hyperbilirubinemia (12.7\%).

Thus, according to the findings obtained in statistical analysis of delivery records in women having multiple pregnancy, 2 cases of miscarriage/stillbirth $\left(2^{\text {nd }}\right.$ fetus in both cases) took place. Congenital brain malformation, anencephaly to be exact, was a primary disease in the first case. Fetal death occurred in utero. The birth of a second child happened at 38 week of pregnancy, the live girl $2890 \mathrm{~g}$ of weight and $51 \mathrm{~cm}$ of height was born, Apgar score of 6-7. In the other case, the cause of miscarriage/stillbirth was perinatal asphyxia (antepartum cause) in women with preeclampsia and severe placental insufficiency followed by intrauterine growth restriction. The pregnant woman gave birth at 34 weeks due to arising signs of severe preeclampsia, the live boy 
$2050 \mathrm{~g}$ in weight, $48 \mathrm{~cm}$ in height was born prematurely, Apgar score of 5-6.

Two newborns died in early neonatal period (newborn twins). The mother delivered 3 prematurely at 32-33 weeks, placental abruption, moderate preeclampsia, severe anemia. Cesarean section was performed, two live girls were born $1600 \mathrm{~g}$ and $1840 \mathrm{~g}$ in weight, $39 \mathrm{~cm}$ and $41 \mathrm{~cm}$ in height, Apgar score of 3-3 and 2-2, respectively, stayed alive for 2 hours 5 minutes and 1 hour 17 minutes. Granulomatous Amebic Encephalitis as an intrauterine infection with chorioamnionitis was the primary disease that led to placental disruption and severe asphyxia in children.

In our opinion such a high occurrence of obstetric complications in women having multiple pregnancy results from a high risk in multiple pregnancy, and the course of pregnancy and labor in such patients is followed by a great number of complications that are way more severe than in singleton pregnancy. Literature indicates that multiple pregnancy develops in the presence of a greater number of complications than singleton. The most common and typical in multiple pregnancy are the following complications: threatened abortion, anemia, preeclampsia, placental insufficiency, intrauterine growth restriction, miscarriage \& stillbirth of one or both fetuses $[1,2,11]$. The above-mentioned clinical features of multiple pregnancy for sure directly affected obstetric and perinatal outcomes of birth in such women.

\section{CONCLUSIONS}

The findings of the statistical analysis of archival delivery records enable to conclude about:

1. Multiple pregnancy is a high risk for anemia in pregnancy $(76.4 \%)$, preeclampsia (52.7\%), placental insufficiency (47.3\%), early intrauterine growth restriction $(27.3 \%)$ and fetal distress in pregnancy and labor (29.1\%).

2. The high rate of obstetric and perinatal complications in these women leads to the high rate of Cesarean section (32.7\%) and asphyxia cases in newborns (35\%).

3. Due to the low effectiveness of widely accepted methods for prediction, treatment and prevention of obstetric and perinatal complications in multiple pregnancy after ART, further research is demanded.

\section{REFERENCES}

1. Kamphuis E.I., Bhattacharya S., van der Veen F. at al.; Evidence Based IVF Group. Are we overusing IVF? BMJ. 2014; 348: 252.

2. American College of Obstetricians and Gynecologists. "Perinatal risks associated with assisted reproductive technology: Committee Opinion No. 67."J Obstet Gynecol. 2016;128: e61-8.

3. Di Nisio M., Ponzano A., Tiboni G.M. et al. Effects of multiple inherited and acquired thrombophilia on outcomes of in-vitro fertilization. Thromb Res. 2018;9 (167):26-31.D01: 10.1016/j.thromres.2018.05.006.

4. Chighizola C.B., Raimondo M.G., Meroni P.L. Does APS Impact Women's Fertility? Curr Rheumatol Rep. 2017;(6):33. D0I: 10.1007/s11926-0170663-7.
5. Vermey B.G., Buchanan A., Chambers G.M. et al. Are singleton pregnancies after assisted reproduction technology (ART) associated with a higher risk of placental anomalies compared with non-ART singleton pregnancies? A systematic review and meta-analysis. BJOG. 2018. doi: 10.1111/1471-0528.15227.

6. Barinov S.V., Rogova E.V., Dolgich T.I. et al. Osobennosti techeniya mnogoplodnoj beremennosti v sochetanii s trombofiliyami [Features of 0 course of polycarpous pregnancy in combination with trombophylia]. Mother and child in Kuzbass. 2014: 2(57): 39-42. (in Russian).

7. Xiang L., Wei Z., Wu J. at al. Clinical significance of first-trimester intrauterine haematomas detected in pregnancies achieved by IVFembryo transfer. Reprod Biomed Online. 2014;4:445-51. doi: 10.1016/j. rbmo.2014.06.015.

8. Adamyan L.V., Arty `muk N.V., Bashmakova N.V. et al Gipertenzivny’e rasstrojstva vo vremya beremennosti, $v$ rodakh i poslerodovom periode. Pree klampsiya. E' klampsiya. Klinicheskie rekomendaczii. [Hypertensive disorders during pregnancy, childbirth and the postpartum period. Preeclampsia. Eclampsia. Clinical guidelines]. Treatment protocol. 2016: 40. (in Russian).

9. UI yanina E.V., Fatkullin I.F., Khajrullina G.R. Markery` angiogeneza i ul' trazvukovogo issledovaniya v oczenke stepeni tyazhesti sindroma zaderzhki razvitiya ploda. [Markers of angiogenesis and ultrasound in assessing the severity of fetal growth retardation syndrome]. The Bulletin of Contemporary Clinical Medicine. 2016;9(5): 79-82. (in Russian).

10. Townsend R., $O^{\prime}$ Brien P., Khalil A. Current best practice in the management of hypertensive disorders in pregnancy. Integr. Blood Press Control. 2016;9:79-94. doi: 10.2147/IBPC. S77344.

11. Barinov S.V., Rogova E. V., Kadczy`na T. V. et al. Prognozirovanie riska tyazheloj pree klampsii pri mnogoplodnoj beremennosti i puti ee profilaktiki. [Prediction of the risk of severe pre-eclampsia in multiple pregnancies and ways of its prevention.] .Bulletin of the Peoples' Friendship University of Russia. Series: Medicine. 2015;1:69-75. (in Russian).

12. Okun N., Sierra S. et al. Pregnancy outcomes after assisted human reproduction. Society of Obstetricians and Gynaecologists of Canada J. Obstet. Gynaecol. Can. 2014;36 (1):64-83.

13. El-Toukhy T., Bhattacharya S., Akande V.A. on behalf of the Royal College of Obstetricians and Gynaecologists. Multiple Pregnanci es Following Assisted Conception. Scientific Impact Paper. 2018: 22.

14. Wang X., Du M., Guan Y.et al. Comparative neonatal outcomes in singleton births from blastocyst transfers or cleavage-stage embryo transfers: a systematic review and meta-analysis. Reprod Biol Endocrinol. 2017;15(1):36. doi: 10.1186/s12958-017-0255-4.

15. Dar S., Librach C.K., Gunby J. et al. Increased risk of preterm birth in singleton pregnancies after blastocyst versus Day 3 embryo transfer: Canadian ART Register (CARTR) analysis. Human Reproduction. 2013; 28(4):924-928.

16. Mascarenhas M., Sunkara S.K., Antonisamy B. et al. Higher risk of preterm birth and low birth weight following oocyte donation: A systematic review and meta-analysis. Eur J Obstet Gynecol Reprod Biol. 2017;218:60-67. doi: 10.1016/j.ejogrb.2017.09.015.

\section{ORCID and contributionship:}

Tamara G. Romanenko: 0000-0003-0157-6223 A,E,F

Olha M. Sulimenko: 0000-0003-1948-8387 A,B,C,D

Svitlana O. Ovcharenko: 0000-0002-2493-7741 ${ }^{C, D}$ 


\section{Conflict of interest:}

The Authors declare no conflict of interest.

\section{CORRESPONDING AUTHOR}

Tamara G. Romanenko

Shupyk National Medical Academy

of Postgraduate Education

of the Ministry of Health of Ukraine

9 Dorohozhytska St., 04112 Kyiv, Ukraine

tel: +380677219619,

e-mail: romanenko.tmr@gmail.com

Received: 12.11 .2020

Accepted: 08.03.2021

A - Work concept and design, B - Data collection and analysis, C - Responsibility for statistical analysis,

D-Writing the article, $\mathbf{E}$ - Critical review, $\mathbf{F}$ - Final approval of the article 